\title{
Chicken or the egg: Warburg effect and mitochondrial dysfunction
}

\section{Deniz Senyilmaz and Aurelio A. Teleman*}

\author{
Address: German Cancer Research Center (DKFZ), Heidelberg, Germany \\ *Corresponding author: Aurelio A. Teleman (a.teleman@dkfz.de) \\ Fl000Prime Reports 2015, 7:4I (doi:10.12703/P7-4I) \\ All Fl000Prime Reports articles are distributed under the terms of the Creative Commons Attribution-Non Commercial License \\ (http://creativecommons.org/licenses/by-nc/3.0/legalcode), which permits non-commercial use, distribution, and reproduction in any medium, \\ provided the original work is properly cited. \\ The electronic version of this article is the complete one and can be found at: http://fl000.com/prime/reports/b/7/4I
}

\begin{abstract}
Compared with normal cells, cancer cells show alterations in many cellular processes, including energy metabolism. Studies on cancer metabolism started with Otto Warburg's observation at the beginning of the last century. According to Warburg, cancer cells rely on glycolysis more than mitochondrial respiration for energy production. Considering that glycolysis yields much less energy compared with mitochondrial respiration, Warburg hypothesized that mitochondria must be dysfunctional and this is the initiating factor for cancer formation. However, this hypothesis did not convince every scientist in the field. Some believed the opposite: the reduction in mitochondrial activity is a result of increased glycolysis. This discrepancy of opinions is ongoing. In this review, we will discuss the alterations in glycolysis, pyruvate metabolism, and the Krebs cycle in cancer cells and focus on cause and consequence.
\end{abstract}

\section{Introduction}

Almost a century ago, Otto Warburg made a very significant observation that would start a long-lasting, heated discussion. He observed that cancer cells, unlike many other cells in the body, opt for glycolysis rather than mitochondrial respiration, even in the presence of oxygen (referred to here as the Warburg effect) [1]. Warburg proposed that the aerobic glycolysis phenotype that he observed stemmed from the fact that cancer cell mitochondria are irreversibly dysfunctional. He believed, in fact, that dysfunctional mitochondria are required and necessary to start all the biochemical events that eventually result in transformation to the cancerous state [2]. His findings went hand-in-hand with Pasteur's postulations. In 1861, Pasteur reported that yeast cells upregulate glycolysis under hypoxic conditions. Given that the inner regions of solid tumors are hypoxic because of anomalous vascularization, Pasteur's effect seemed to explain Warburg's observation. However, the biochemist Weinhouse was not convinced by Warburg's explanation of cancer initiation by damaged mitochondria $[3,4]$. As a pioneer of isotope tracer usage in biochemistry, he found that cancer cells are able to oxidize glucose and fatty acids to carbon dioxide at levels comparable to those of normal cells [5]. He argued that the reverse was true: cancer cells have reduced mitochondrial activity as a consequence of heightened glycolytic flux, which is known to inhibit mitochondria-the so-called Crabtree effect $[6,7]$. To this day, the field has not been able to reach a conclusive decision on this matter. To explore the relationship between these two views, we use the chicken-and-egg analogy: it is difficult to determine whether mitochondrial dysfunction emerges first, thereby forcing cells to rely on glycolysis, or whether the reverse occurs, whereby increased glycolytic flux takes place first, which in turn suppresses mitochondrial respiration. There are data supporting both of the models in different contexts. In this review, we will discuss the two different points of view in relation to glycolysis, pyruvate metabolism, and the Krebs cycle.

\section{Changes in the glycolytic pathway during tumorigenesis}

As Warburg noticed, cancer cells have elevated levels of glucose uptake compared with non-cancer cells. These findings have been confirmed by using recent technological developments that allow non-invasive monitoring of glucose uptake in vivo, called 2-fluoro-6-deoxyglucose positron emission tomography (FDG-PET). In this technique, a traceable glucose analog is used that is 
recognized and taken up by glucose transporters (GLUTs) but cannot be used for downstream glycolytic reactions. Hence, the glucose analog accumulates in cells and can be visualized and quantified by PET. This technique also allows diagnosis and localization of tumors. With FDG-PET, glucose uptake has been shown to increase in certain tumors [8], and higher FDG uptake has been correlated with poor cancer prognosis [9-11].

Multiple observations outlined below, however, suggest that glycolytic flux in cancer cells is upregulated as a result of multiple changes in signaling pathways and not necessarily as a result of impaired mitochondrial function. Glycolysis begins with cellular uptake of glucose via GLUTs on the cell surface (Figure 1). In 1974, Hatanaka proposed that cells upregulate GLUTs in order to meet increased glucose demand upon transformation [12]. Later studies showed that, indeed, levels of GLUTs, especially the high-affinity GLUTs 1 and 3, were upregulated in a plethora of tumor types (nicely reviewed in $[13,14])$. Moreover, GLUT1 transcription is upregulated in response to hypoxia $[15,16]$ and inhibition of mitochondrial respiration [17], both conditions in which cells need to divert the metabolic flux from mitochondrial respiration to glycolysis. Furthermore, in tumors with high insulin signaling, GLUT4 is enriched at the cell membrane as a consequence of elevated PI3K/ Akt signaling (reviewed in [18]) and GLUT1 transcription is upregulated via the serine/threonine kinase AKT [19]. The human genome actually has three families of GLUTs, namely SLC2A, SLC5A, and SLC50A, with a total of 27 members [20]. These members are differentially regulated in various tumor types. These findings could suggest that upregulation of glucose uptake and hence glycolytic flux is a primary alteration in cancer and not a consequence of impaired mitochondrial function. That said, activity of GLUTs is also strongly driven by activation of AMP-activated protein kinase (AMPK) [21], and AMPK can be activated by an adenosine triphosphate (ATP) decrease caused by mitochondrial dysfunction. Therefore, increased glucose uptake could also result from mitochondrial dysfunction. This nicely illustrates the fact that glycolytic flux and mitochondrial function are so intertwined that it is difficult to determine what is cause and what is consequence.

After uptake into the cell, the next step in glycolysis is phosphorylation of glucose to glucose-6-phosphate by hexokinase (HK) (Figure 1). There are four isoforms of HK and upon transformation, isoform II, the isoform with the highest enzymatic activity, becomes the prevalent isoform in the cell [22] and this is due in part to HIF1 $\alpha$ (hypoxia-induced factor $1 \alpha$ )-dependent transcriptional upregulation [23]. HKI and especially
HKII are known to interact with voltage-dependent anion channels (VDACs) on the mitochondrial outer membrane of rapidly proliferating cells. This interaction is important for the inhibition of apoptosis by blocking cytochrome c release into the cytoplasm [24]. This helps cells evade apoptosis, one of the six hallmarks of cancer [25]. For these reasons, the VDAC-HKII interaction is a potential target for cancer therapy. There are data showing that the VDAC-HKII interaction favors glycolysis by inhibiting a negative feedback of HKII by its own product and by stabilizing HKII protein $[26,27]$. Thus, HKII offers a mechanistic explanation for the Warburg effect independently of mitochondrial dysfunction.

Glucose-6-phosphate is next converted to fructose-6phosphate by phosphoglucose isomerase (PGI) (Figure 1). Expression of PGI is induced in response to HIF- $1 \alpha$ and vascular endothelial growth factor (VEGF) signaling, both of which are often deregulated in tumors [28]. Interestingly, PGI acts as a cytokine outside of the cell. Secreted PGI is a tumor marker, as it can be detected in serum and urine of patients with cancer [29,30]. PGI is also called AMF (autocrine motility factor) because treatment of fibrosarcoma cells with purified PGI protein induces cell migration [31], implicating it in metastasis. Furthermore, mere PGI gain of function is sufficient to drive cell proliferation in 3T3 fibroblasts [32]. All in all, PGI can be considered an oncogene.

Next, fructose-6-phosphate is phosphorylated again to yield fructose-1,6-bisphosphate (Figure 1). This step is of particular importance for regulation of metabolism for several reasons. Firstly, it is the rate-limiting reaction. Secondly, the fact that ATP, its own substrate, allosterically inhibits phosphofructokinase 1 and 2 (PFK1 and 2) [33-35] offers an explanation for the Pasteur effect: inhibition of glycolysis by mitochondrial respiration. Thirdly, this is a decision point for glucose to enter further into glycolysis or to be diverted into the pentose phosphate pathway (PPP). The PPP has two branches: an irreversible, oxidative branch that starts with glucose-6phosphate and generates reduced nicotinamide adenine dinucleotide phosphate (NADPH) and a reversible, nonoxidative branch that interconverts 5-carbon sugars and produces no NADPH (Figure 1). Hence, changes in PFK activity influence how much glucose enters the oxidative branch of PPP, yielding reducing equivalents for fatty acid biosynthesis and reactive oxygen species (ROS) defense (Figure 1). One critical factor determining PFK1 activity is the level of fructose-2-6-biphosphate, which is the product of the bifunctional enzyme phosphofructokinase 2/fructosebisphosphatase (PFKB). Fructose-2, 6-bisphosphate allosterically activates PFK1, thereby counteracting ATP inhibition [36,37]. PFKB has four 
Figure I. In cancer, glycolytic flux is increased through upstream parts of the glycolytic pathway up to pyruvate kinase and then decreased from pyruvate kinase downward, thereby generating a 'bottleneck'

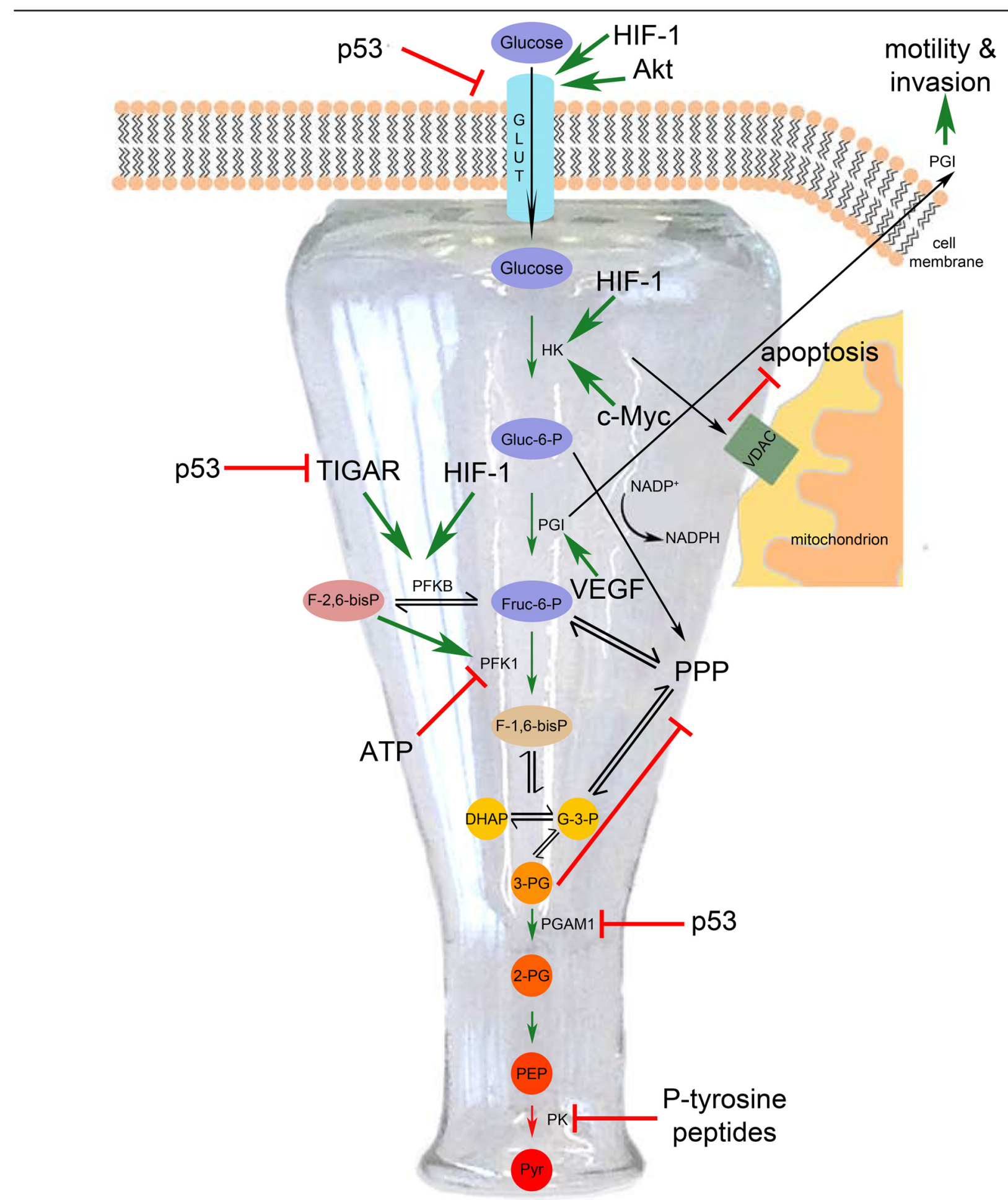

DHAP, dihydroxyacetone phosphate; F-I,6-bisP, fructose-1,6-bisphosphate; Fruc-6-P, fructose-6-phosphate; Gluc-6-P, glucose-6-phosphate; GLUT, glucose transporter; HIF-I, hypoxia-induced factor I; HK, hexokinase; PEP, phosphoenolpyruvate; PFK, phosphofructokinase; PG, phosphoglycerate; PGAMI, phosphoglycerate mutase I; PGI, phosphoglucose isomerase; PK, pyruvate kinase; pyr, pyruvate; PPP, pentose phosphate pathway; TIGAR, TP53-induced glycolysis and apoptosis regulator; VDAC, voltage-dependent anion channel; VEGF, vascular endothelial growth factor. 
isozymes that are expressed in a tissue-specific manner; however, PFKBP3, which has the highest kinase activity, is upregulated in high-grade astrocytomas and malignant breast and colon tumors $[38,39]$, tipping the scale of the bidirectional reaction in favor of fructose-2,6bisphosphate production. This sustains increased glycolytic activity rather than PPP. Upregulation of PFKB expression and activity occurs in various ways. A recent publication showed that methylation stabilizes PFKB3 in U937 human leukemia cells [40]. All PFKB isoforms are upregulated in response to hypoxia in vivo, PFKBP3 being induced to the largest extent [41]. In addition to PFKB3, PFKB4 has been also found to be important for cancer cell survival via small interfering RNA (siRNA) screens in two different models: glioma stem-like cells [42] and prostate cancer cell lines [43]. Another critical factor controlling PFK activity is the p53 tumor suppressor-mediated induction of TIGAR (TP53induced glycolysis and apoptosis regulator). TIGAR negatively regulates PFK2 activity and lowers fructose-2,6bisphosphate levels, and thereby reduces PFK1 activity and diverts glucose into the PPP rather than glycolysis [44]. In tumors with p53 loss of function, TIGAR thereby contributes to the increase in glycolytic rate. p53 has additional regulatory roles in metabolism, such as downregulating GLUT1 and GLUT4 expression at the transcriptional level [45].

Phosphoglycerate mutase 1 (PGAM1) is another glycolytic enzyme whose activity is increased in several tumor types, including hepatocellular carcinoma [46]. Its protein level is negatively regulated by p53 [47]. PGAM1 converts 3-phosphoglycerate to 2-phosphoglycerate (Figure 1). Its activity is important in metabolic regulation because its substrate, 3-phosphoglycerate, inhibits flux through the oxidative branch of PPP [48], thereby diverting glucose into glycolysis. Therefore, upregulation of PGAM1 is advantageous for cell proliferation, although it renders tumor cells sensitive to oxidative stress due to reduction in NADPH production from the oxidative branch of PPP.

\section{Pyruvate: the intersection}

So far, we have discussed the steps of glycolysis through which flux is increased in cancer cells. Interestingly, cancer cells do not increase flux in all steps of glycolysis. Although flux through the upstream steps is increased, they often exhibit a bottleneck in the following steps of glycolysis leading from phosphoenolpyruvate (PEP) to the Krebs cycle and this is for the reasons discussed below.

Pyruvate kinase (PK) is an important node of control in cancer cell metabolism. It catalyzes the conversion of
PEP to pyruvate (Figure 1). PK has two isoforms produced by alternative splicing of $P K M$, namely $M 1$, and M2, which are spatially and temporally differentially expressed. PKM1 is expressed mainly during adulthood, and PKM2 is expressed during embryogenesis. The alternatively spliced transcripts of $P K L R$, the $\mathrm{L}$ and $\mathrm{R}$ isoforms, on the other hand, are expressed specifically in liver [49]. In 2008, it was shown that expressing PKM2 confers a proliferative advantage to tumor cells [50]. In fact, depletion of PKM2 expression in cancer cell lines and reconstitution with PKM1 led to inhibition of growth and reversal of the Warburg phenotype [50]. This finding was unexpected because at first glance it does not fit into the model that cancer cells have increased glycolytic flux. PKM2 is the isoform with lower enzymatic activity and therefore it slows down this glycolytic reaction. However, generating a bottleneck at the end of the glycolytic pathway appears to be necessary for giving intermediates the time to flux through alternative pathways, such as PPP, that are of crucial importance for replenishing building blocks required for growth and proliferation [49]. PPP flux is especially needed in cancer cells for the production of pentose phosphates, which are used for nucleotide biosynthesis, and for the production of NADPH, which is a reducing equivalent needed both for fatty acid and sterol biosynthesis [51] and for mounting an anti-oxidant response to ROS by re-oxidizing glutathione [52]. PKM2 is also subject to negative regulation by phosphotyrosine peptides. Since tyrosine kinase signaling is often deregulated in a cancer setting, this regulation could be another way of pushing glycolytic intermediates into anabolic pathways such as the PPP [53]. Another advantage that selective PKM2 expression confers to cancer cells is the accumulation of its substrate, PEP. PEP acts as a phosphate donor to phosphorylate PGAM1 at the catalytic histidine, thereby increasing its activity [54]. Interestingly, the functional relevance of PKM2 in tumor development was analyzed in a recent study in which mice specifically lacking the PKM2 isoform were found to develop breast tumors and liver metastases induced by BRCA1 loss of function, indicating that PKM2 per se is not required for tumor development [55]. Tumor cells had compensatory PKM1 expression, although PKM1 levels were heterogenous throughout the tumor. Whereas non-proliferating tumor cells exhibited higher PKM1 expression, proliferating cells did not [55]. The same study also analyzed human tumor samples and reported the presence of tumor samples with no detectable PK expression. Even though further studies are required, these findings hint that proliferating cells can lack PK activity altogether. It appears that PKM2 expression per se is not required. Rather, the outcome of reduced PK activity is what favors cell proliferation. 
Pyruvate is the critical node where the flux of glucosederived carbons is determined, either toward lactate which is usually secreted or into mitochondria (Figure 2). As Warburg observed, cancer cells metabolize pyruvate by aerobic glycolysis and produce lactate. Here, we will discuss the mechanisms of aerobic glycolysis induction which do not necessarily stem from dysfunctional mitochondria, which would have pleased Weinhouse.

The first possibility for pyruvate is to be reduced to lactate by lactate dehydrogenase (LDH). The prevalent isoform of LDH is LDHA. Like many other glycolytic genes, $L D H A$ is induced by both HIF-1 $\alpha$ [56] and c-myc [57]. Another means of inducing LDHA activity in the context of cancer is via phosphorylation at the tyrosine 10 residue [58]. Reflecting the importance of the Warburg effect for cancer cell survival, loss of function of LDHA by means of either siRNA depletion or pharmacological inhibition forces mitochondria to respire and slows down proliferation $[59,60]$. To maintain intracellular $\mathrm{pH}$ homeostasis, cells need to evacuate the resulting lactate to the extracellular space. Indeed, loss of function of the hypoxia-responsive lactate $/ \mathrm{H}^{+}$symporter MCT4 (monocarboxylate transporter 4) [61] impairs tumor growth [62], thereby rendering MCT4 a good therapeutic target.

The second possibility of pyruvate utilization is to send it to mitochondria for further oxidation in the Krebs cycle.

Figure 2. In cancer cells, reduction of pyruvate to lactate and its secretion is favored rather than pyruvate entry into mitochondria and the Krebs cycle

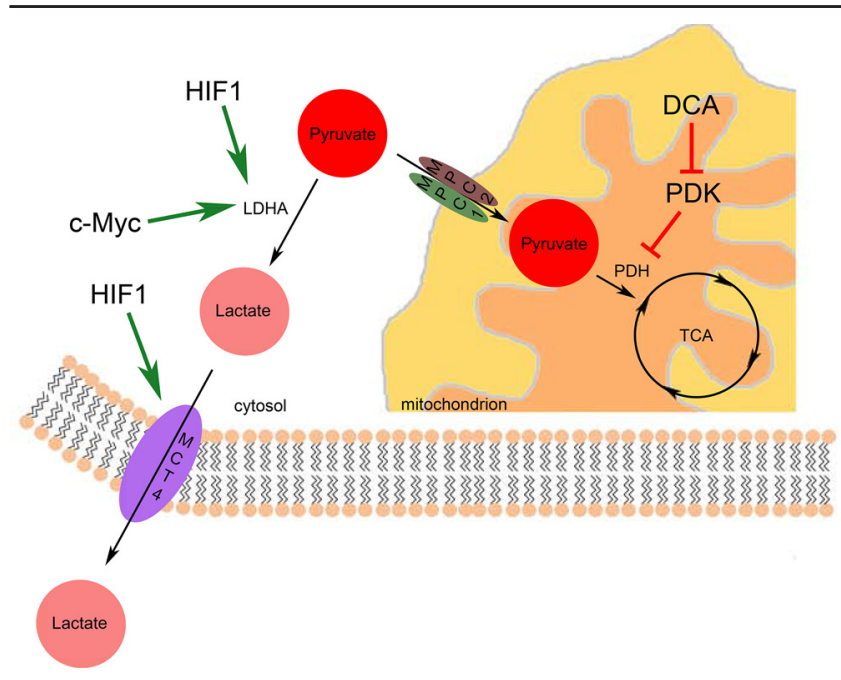

DCA, dichloroacetate; HIFI, hypoxia-induced factor I; LDHA, lactate dehydrogenase A; MCT4, monocarboxylate transporter 4; MPC, mitochondrial pyruvate carrier; PDH, pyruvate dehydrogenase; PDK, pyruvate dehydrogenase kinase; TCA, tricarboxylic acid.
The limiting step here is the entry of pyruvate into mitochondria by mitochondrial pyruvate carriers (MPCs) (Figure 2). The activity and chemical inhibition of a MPC were shown in 1974 [63], but the molecular identities of these carriers remained a secret until 2012, when they were identified as MPC1 and MPC2 $[64,65]$. The cancer relevance of these carriers was thoroughly investigated very recently [66-68]. In MPC1 loss-offunction tumor models, forced expression of the protein leads to activation of mitochondrial pyruvate oxidation, which inhibits anchorage-independent growth of colon cancer cells [68]. These studies indicate that MPC loss of function could be one means of rewiring cancer metabolism toward aerobic glycolysis, the Warburg effect. In tumor types with reduced MPC activity, it could be used as a therapeutic target. The fact that forced activation of MPC can activate mitochondrial respiration suggests that mitochondria are not necessarily irreversibly damaged, as Warburg claimed. Upon entry into mitochondria, pyruvate is converted to acetyl coenzyme A (CoA) and joins the Krebs cycle, during which reduced nicotinamide adenine dinucleotide $(\mathrm{NADH})$ and precursors for anabolic pathways are generated (Figure 3A).

At this stage, there is one more regulation point, pyruvate dehydrogenase (PDH). PDH is negatively regulated by NADH and acetyl CoA and through phosphorylation by pyruvate dehydrogenase kinase (PDK) $[69,70]$. PDK is a direct target of HIF1 $[71,72]$. HIF1 upregulates PDK transcription in response to hypoxia to reduce mitochondrial utilization of glucose. Moreover, oncogenic tyrosine kinases contribute to the reduction of PDH activity in two ways: they phosphorylate PDK to increase its activity [73] and they phosphorylate and inhibit a phosphatase that acts on PDH [74]. Dicholoroacetate (DCA) is a pharmacological inhibitor of PDK [75-78], which is used in treatment of lactic acidosis and cancer. The fact that DCA treatment is able to reverse Warburg phenotypes [76] is another indication that mitochondria do not have to be irreversibly damaged.

\section{'Hacking' the Krebs cycle}

Even though cancer cells tend to use glucose in aerobic glycolysis rather than oxidizing it in the Krebs cycle, the Krebs cycle is not dispensable altogether. The Krebs cycle constitutes a chain of reactions that are essential for the production of building blocks for growth and proliferation. As anabolic reactions use substrates from the Krebs cycle, thereby depleting the Krebs cycle, the cell needs to replenish these intermediates via a set of so-called anaplerotic reactions [79]. For example, Vacanti and colleagues [66] made the observation that, upon inhibition of pyruvate entry into mitochondria in C2C12 myotubes, cells were able to maintain Krebs cycle 
metabolism without any drastic changes in the levels of intermediates, even though they exhibit a reduction in the mitochondrial oxidation of pyruvate. Cancer cells that divert glucose metabolism away from mitochondria face a situation similar to pyruvate entry inhibition and therefore employ strategies to keep the cycle going, discussed below. By this means, they use mitochondria for biosynthesis rather than degradation.

One of the anaplerosis strategies is glutaminolysis (Figure 3A). Cells use glutamine as a carbon source to feed the Krebs cycle [80]. Glutamine is first converted to glutamate by glutaminase (GLS). Next, glutamate is converted to $\alpha$-ketoglutarate $(\alpha-K G)$ either by a transamination reaction of the amine group onto another ketoacid or by deamination [81]. Myc, which is activated in most cancer types, increases glutaminolytic activity by increasing expression of GLS and the glutamine transporter ASCT2 (ASC amino acid transporter 2) [82]. If a particular tumor uses this strategy to keep the Krebs cycle filled, it renders the cancer cells addicted to glutamine. The filling of the Krebs cycle via glutaminolysis is then used for several cataplerotic reactions important for cancer cell lipid biosynthesis: (1) malate is converted to pyruvate by malic enzyme (ME) in the cytosol, thereby yielding NADPH (Figure 3A), which is a reducing equivalent used for fatty acid biosynthesis; (2) oxaloacetate (OAA) is converted back to malate and also exported to yield NADPH; and (3) citrate is used as a source of acetyl CoA for fatty acid synthesis [83] (Figure $3 \mathrm{~A})$. The relative contribution of these reactions via $\mathrm{ME}$ to the NADPH pool is quite significant and is roughly equivalent to the NADPH production by the PPP [84].

Although glutaminolysis can replenish Krebs cycle intermediates, it still requires functional mitochondria and oxygen, which are not always available in the tumor context. Cancer cells use reductive carboxylation in cases of defective mitochondria [85] and hypoxia [86,87] (Figure 3B). This pathway involves NADPH-dependent reductive carboxylation of $\alpha-K G$ (that derives from glutaminolysis, see above paragraph) by isocitrate dehydrogenase (IDH) into isocitrate, which is the reverse reaction of the conventional Krebs cycle. Isocitrate is subsequently isomerized to citrate, which is essential for lipid biosynthesis. Substrate availability also influences the direction of the reaction: that is, reductive carboxylation or oxidative decarboxylation of $\alpha$-KG. A high NADPH/ $\mathrm{NADP}^{+}$(nicotinamide adenine dinucleotide phosphate) ratio, low citrate levels, and high $\alpha-K G$ abundance increase the reductive carboxylation activity of cells [88-91].

Cancer cells need to upregulate their fatty acid biosynthesis upon neoplastic transformation $[92,93]$ in order to meet the increased demand of membrane production due to increased proliferation. Citrate production is of importance for fatty acid biosynthesis because the citrate shuttle transports mitochondrial acetyl CoA across the membranes to the cytoplasm, where it is converted back to OAA and acetyl CoA by ATP citrate lyase [94] (Figure 3A and B). This is one of the reasons why anaplerotic reactions are crucial for supporting growth and proliferation of the tumor cells.

\section{Warburg was not totally wrong}

So far, we have discussed mechanisms that promote aerobic glycolysis independently of possible mitochondrial defects. However, there are cases where Warburg was right, whereby mutation of genes whose products act in mitochondria are enough to induce transformation. Discussed below are examples of such cases.

Various cancer types have been found to harbor neomorphic mutations in IDH1 and IDH2 enzymes, causing them to lose their activity of decarboxylation of isocitrate to $\alpha-K G$, and to gain the activity of converting $\alpha-K G$ to the oncometabolite 2-hydroxyglutarate (2-HG) [95,96] (Figure 3A). The prevalent view on the mechanism of 2-HG-induced tumor formation is that it alters cellular methylation of both DNA and proteins. There is evidence that 2-HG competitively inhibits $\alpha$-KG-dependent dioxygenases, such as methylcysteine hydroxylases and the Jumonji C (JmjC) family of histone demethylases [97-99]. Data also show that 2-HG stabilizes HIF-1 $\alpha$ by inhibiting prolyl hydroxylases (PHDs) (also $\alpha$-KG-dependent dioxygenases) [98].

Some enzymes in the Krebs cycle function as tumor suppressors. For example, mutations in succinate dehydrogenase (SDH) subunits have been associated with hereditary paraganglioma $[100,101]$, and fumarate hydratase $(F H)$ mutations were implicated in renal cell cancers and smooth muscle tumors [102]. In both cases, substrates of the enzymes, succinate and fumarate, respectively, have been shown to accumulate. The mechanism of SDH and FH stemmed carcinogenesis is induction of a 'pseudohypoxia' state. Hypoxia-responsive genes are regulated by the transcription factor HIF1 $\alpha$. Under normoxic conditions, HIF1 $\alpha$ is constantly hydroxylated at proline residues by PHDs. Upon hydroxylation, HIF1 $\alpha$ is readily recognized and ubiquitinated by Von HippelLindau complex that has E3 ubiquitin ligase activity $[103,104]$. PHDs use $\alpha-K G$ as cofactors and generate succinate at the end of the reaction [105]. In the context of SHD and FH mutations, cytosolic succinate $[106,107]$ and fumarate [108] concentrations increase and they inhibit the activity of PHDs, leading to stabilization of HIF1 $\alpha$ (Figure 3A) even in the presence of oxygen and induction of an aberrant hypoxic response [109]. 
Figure 3. Krebs cycle reactions are altered but not completely abrogated in cancer cells

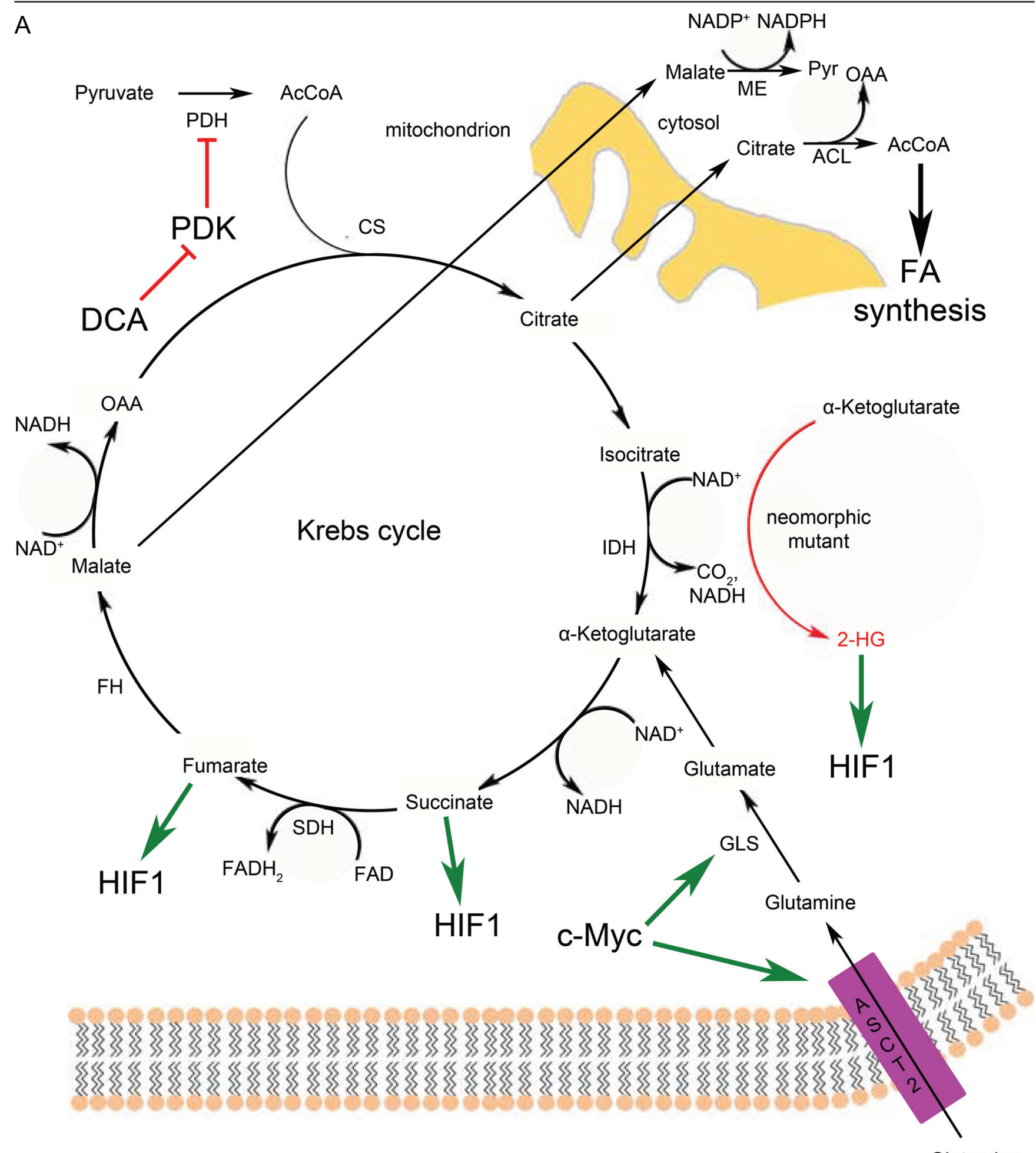

Glutamine

(A) Full Krebs cycle in the presence of functional mitochondria and oxygen. Cancer cells use glutamine more than pyruvate for anaplerosis. 
Figure 3. Continued

B

\section{mitochondrion}

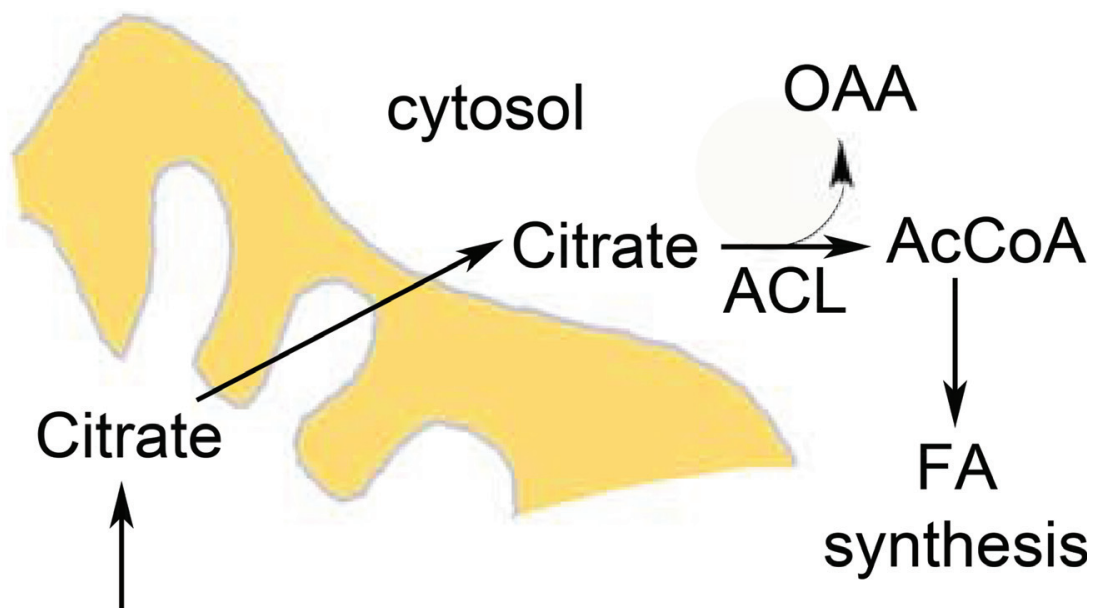

\section{Isocitrate}
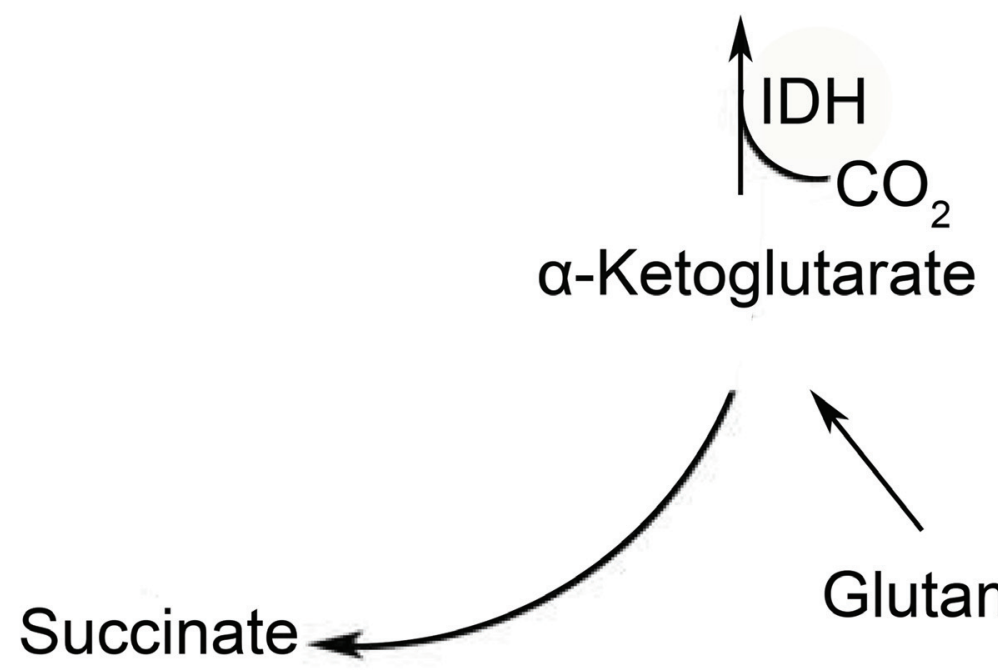

\section{Glutamate}

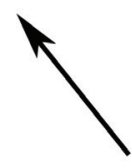

Glutamine

(B) A truncated form of the Krebs cycle is favored in cancer cells with defective mitochondria or under hypoxic conditions (or both) to generate metabolic precursors with reductive carboxylation. 2-HG, 2-hydroxyglutarate; AcCoA, acetyl coenzyme A; ACL, ATP citrate lyase; ASCT2, sodium-dependent neutral amino acid transporter type 2; CS, citrate synthase; DCA, dichloroacetate; FA, fatty acid; FAD, flavin adenine dinucleotide; FH, fumarate hydratase; GLS, glutaminase; HIFI, hypoxia-induced factor I; IDH, isocitrate dehydrogenase; ME, malic enzyme; NAD, nicotinamide adenine dinucleotide; NADH, reduced nicotinamide adenine dinucleotide; NADP, nicotinamide adenine dinucleotide phosphate; NADPH, reduced nicotinamide adenine dinucleotide phosphate; OAA, oxaloacetate; PDH, pyruvate dehydrogenase; PDK, pyruvate dehydrogenase kinase; pyr, pyruvate; SDH, succinate dehydrogenase.

\section{Conclusions}

There has been discussion for almost a century about the reasons for the metabolic phenotypes that Warburg initially observed, i.e. that cells use glucose via glycolytic reactions instead of respiration, even in the presence of oxygen. It is a phenomenon that appears counterintuitive and wasteful, given how little ATP glycolysis yields compared with oxidative phosphorylation. The 
main disagreement revolves around Warburg's proposal that irreversible damage of mitochondria is the main reason for carcinogenesis. In some cases, Warburg's proposal holds true. For example, the fact that mutations in some Krebs cycle enzymes, such as $\mathrm{SDH}$ and $\mathrm{FH}$, are able to induce renal tumors indicates that mitochondrial dysfunction can be sufficient for tumor formation. However, there are reports that in some cases cancer cell mitochondrial function is intact. When they are forced to respire, they are able to. In sum, it seems that mitochondrial dysfunction is usually the consequence of tumor formation, yet there are cases in which mitochondrial dysfunction is the cause of the tumor formation. Indeed, one recent study suggests that glycolysis is needed for sustaining stemness and proliferation, whereas forced activation of mitochondrial respiration induces differentiation and reduces proliferation [110]. There seems to be a very strong, yet not very wellunderstood, crosstalk between the regulation of proliferation and a preference for glycolysis.

\section{Abbreviations}

2-HG, 2-hydroxyglutarate; $\alpha-K G, \alpha$-ketoglutarate; AMPK, AMP-activated protein kinase; ATP, adenosine triphosphate; CoA, coenzyme A; DCA, dicholoroacetate; FDG, 2-fluoro-6-deoxyglucose; FH, fumarate hydratase; GLS, glutaminase; GLUT, glucose transporter; HIF, hypoxia-induced factor; HK, hexokinase; IDH, isocitrate dehydrogenase; LDH, lactate dehydrogenase; MCT4, monocarboxylate transporter 4; $\mathrm{ME}$, malic enzyme; $\mathrm{MPC}$, mitochondrial pyruvate carrier; $\mathrm{NADH}$, reduced nicotinamide adenine dinucleotide; NADPH, reduced nicotinamide adenine dinucleotide phosphate; OAA, oxaloacetate; $\mathrm{PDH}$, pyruvate dehydrogenase; PDK, pyruvate dehydrogenase kinase; PEP, phosphoenolpyruvate; PET, positron emission tomography; PFK, phosphofructokinase; PFKBP, phosphofructokinase/ fructosebisphosphatase; PGAM, phosphoglycerate mutase; PGI, phosphoglucose isomerase; PHD, prolyl hydroxylase; PK, pyruvate kinase; PPP, pentose phosphate pathway; ROS, reactive oxygen species; $\mathrm{SDH}$, succinate dehydrogenase; siRNA, small interfering RNA; TIGAR, TP53-induced glycolysis and apoptosis regulator; VDAC, voltage-dependent anion channel.

\section{Disclosures}

The authors declare that they have no disclosures.

\section{References}

I. Warburg O: The Metabolism of Carcinoma Cells. J Cancer Res 1925, 9:148-63.

2. Warburg O: On the origin of cancer cells. Science 1956, 1 23:309-14.

3. Weinhouse S: The Warburg hypothesis fifty years later. Cancer Res Clin Oncol 1976, 87: I15-26.
4. Weinhouse S: On respiratory impairment in cancer cells. Science 1956, 124:267-9.

5. Weinhouse S, Millington RH, Wenner CE: Metabolism of neoplastic tissue. I. The oxidation of carbohydrate and fatty acids in transplanted tumors. Cancer Res 195 I, I I:845-50.

6. Sussman I, Erecinska M, Wilson DF: Regulation of cellular energy metabolism: the Crabtree effect. Biochim Biophys Acta 1980, 59l:209-23.

7. Crabtree H.G: Observations on the carbohydrate metabolism of tumours. Biochem J 1929, 23:536-45.

8. Endo K, Oriuchi N, Higuchi T, lida Y, Hanaoka H, Miyakubo M, Ishikita T, Koyama K: PET and PET/CT using I8F-FDG in the diagnosis and management of cancer patients. Int J Clin Oncol 2006, I I:286-96.

9. Kitajima K, Suenaga Y, Kanda T, Miyawaki D, Yoshida K, Ejima Y, Sasaki R, Komatsu H, Saito M, Otsuki N, Nibu K, Kiyota N, Minamikawa T, Sugimura K: Prognostic value of FDG PET imaging in patients with laryngeal cancer. PLoS One 20I4, 9: e96999.

\section{FlOOOPrime}

RECOMMENDED

10. Dooms C, van Baardwijk A, Verbeken E, van Suylen RJ, Stroobants S, De Ruysscher D, Vansteenkiste J: Association between I8Ffluoro-2-deoxy-D-glucose uptake values and tumor vitality: prognostic value of positron emission tomography in earlystage non-small cell lung cancer. J Thorac Oncol 2009, 4:822-8.

II. Halfpenny W, et al.: FDG-PET. A possible prognostic factor in head and neck cancer. Br J Cancer 2002, 86:5I 2-6.

12. Hatanaka M, Hain SF, Biassoni L, Maisey MN, Sherman JA, McGurk M: Transport of sugars in tumor cell membranes. Biochim Biophys Acta, 1974, 355(1): p. 77-104.

13. Szablewski L: Expression of glucose transporters in cancers. Biochim Biophys Acta 2013, I 835:164-9.

14. Medina RA, Owen GI: Glucose transporters: expression, regulation and cancer. Biol Res 2002, 35:9-26.

15. Chen C, Pore N, Behrooz A, Ismail-Beigi F, Maity A: Regulation of glut I mRNA by hypoxia-inducible factor-I. Interaction between H-ras and hypoxia. J Biol Chem 200I, 276:9519-25.

16. Murakami T, Nishiyama T, Shirotani T, Shinohara Y, Kan M, Ishii K, Kanai F, Nakazuru S, Ebina $Y$ : Identification of two enhancer elements in the gene encoding the type I glucose transporter from the mouse which are responsive to serum, growth factor, and oncogenes. J Biol Chem 1992, 26:9300-6.

17. Ebert BL, Firth JD, Ratcliffe PJ: Hypoxia and mitochondrial inhibitors regulate expression of glucose transporter-I via distinct Cis-acting sequences. J Biol Chem 1995, 270:29083-9.

18. Holman GD, Cushman SW: Subcellular localization and trafficking of the GLUT4 glucose transporter isoform in insulinresponsive cells. Bioessays 1994, 16:753-9.

19. Barthel A, Okino ST, Liao J, Nakatani K, Li J, Whitlock JP Jr, Roth RA: Regulation of GLUTI gene transcription by the serine/ threonine kinase AktI. J Biol Chem 1999, 274:2028I-6.

20. Wright EM: Glucose transport families SLC5 and SLC50. Mol Aspects Med 2013, 34:183-96.

21. Hardie DG, Ross FA, Hawley SA: AMPK: a nutrient and energy sensor that maintains energy homeostasis. Nat Rev Mol Cell Biol 2012, 13:251-62.

22. Mathupala SP, Ko YH, Pedersen PL: Hexokinase II: cancer's double-edged sword acting as both facilitator and gatekeeper of malignancy when bound to mitochondria. Oncogene 2006, 25:4777-86.

23. Kim JW, Gao P, Liu YC, Semenza GL, Dang CV: Hypoxia-inducible factor I and dysregulated c-Myc cooperatively induce vascular endothelial growth factor and metabolic switches hexokinase $\mathbf{2}$ and pyruvate dehydrogenase kinase I. Mol Cell Biol 2007, 27:7381-93.

24. Azoulay-Zohar H, Israelson A, Abu-Hamad S, Shoshan-Barmatz V: In self-defence: hexokinase promotes voltage-dependent anion 
channel closure and prevents mitochondria-mediated apoptotic cell death. Biochem J 2004, 377:347-55.

25. Hanahan D, Weinberg RA: The hallmarks of cancer. Cell 2000, 100:57-70.

26. Bustamante E, Pedersen PL: High aerobic glycolysis of rat hepatoma cells in culture: role of mitochondrial hexokinase. Proc Natl Acad Sci U S A 1977, 74:3735-9.

27. Pedersen PL, Mathupala S, Rempel A, Geschwind JF, Ko YH: Mitochondrial bound type II hexokinase: a key player in the growth and survival of many cancers and an ideal prospect for therapeutic intervention. Biochim Biophys Acta 2002, I555: 14-20.

28. Funasaka $T$, Yanagawa $T$, Hogan $V$, Raz A: Regulation of phosphoglucose isomerase/autocrine motility factor expression by hypoxia. FASEB J 2005, 19:1422-30.

29. Filella X, Molina R, Jo J, Mas E, Ballesta AM: Serum phosphohexose isomerase activities in patients with colorectal cancer. Tumour Biol I 99I, I:360-7.

30. Baumann M, Kappl A, Lang T, Brand K, Siegfried W, Paterok E: The diagnostic validity of the serum tumor marker phosphohexose isomerase (PHI) in patients with gastrointestinal, kidney, and breast cancer. Cancer Invest 1990, 8:35I-6.

31. Watanabe H, Carmi P, Hogan V, Raz T, Silletti S, Nabi IR, Raz A: Purification of human tumor cell autocrine motility factor and molecular cloning of its receptor. J Biol Chem 1991, 266: $13442-8$

32. Tsutsumi S, Yanagawa T, Shimura T, Fukumori T, Hogan V, Kuwano H, Raz A: Regulation of cell proliferation by autocrine motility factor/phosphoglucose isomerase signaling. J Biol Chem 2003, 278:32165-72.

33. Cabrera R, Baez M, Pereira HM, Caniuguir A, Garratt RC, Babul J: The crystal complex of phosphofructokinase-2 of Escherichia coli with fructose-6-phosphate: kinetic and structural analysis of the allosteric ATP inhibition. J Biol Chem 20II, 286:5774-83.

34. Kotlarz D, Buc $\mathrm{H}$ : Regulatory properties of phosphofructokinase 2 from Escherichia coli. Eur J Biochem 198I, I 17:569-74.

35. Atkinson DE, Walton GM: Kinetics of Regulatory Enzymes. Escherichia Coli Phosphofructokinase. J Biol Chem 1965, 240:757-63.

36. Yalcin A, Telang S, Clem B, Chesney J: Regulation of glucose metabolism by 6-phosphofructo-2-kinase/fructose-2,6bisphosphatases in cancer. Exp Mol Pathol 2009, 86: 174-9.

37. Wu C, Khan SA, Peng LJ, Lange AJ: Roles for fructose-2,6bisphosphate in the control of fuel metabolism: beyond its allosteric effects on glycolytic and gluconeogenic enzymes. Adv Enzyme Regul 2006, 46:72-88.

38. Kessler R, Bleichert F, Warnke JP, Eschrich K: 6-Phosphofructo-2kinase/fructose-2,6-bisphosphatase (PFKFB3) is up-regulated in high-grade astrocytomas. J Neurooncol 2008, 86:257-64.

\section{FlOOOPrime \\ RECOMMENDE}

39. Minchenko $\mathrm{OH}$, Ochiai A, Opentanova IL, Ogura T, Minchenko DO, Caro J, Komisarenko SV, Esumi $\mathrm{H}$ : Overexpression of 6phosphofructo-2-kinase/fructose-2,6-bisphosphatase-4 in the human breast and colon malignant tumors. Biochimie 2005, 87: $1005-10$

\section{FlOOOPrime RECOMMENDED}

40. Yamamoto T, Takano N, Ishiwata K, Ohmura M, Nagahata $Y$, Matsuura T, Kamata A, Sakamoto K, Nakanishi T, Kubo A, Hishiki T, Suematsu M: Reduced methylation of PFKFB3 in cancer cells shunts glucose towards the pentose phosphate pathway. Nat Commun 2014, 5:3480

\section{FlOOOPrime}

\section{RECOMMENDED}

41. Minchenko OI, Opentanova I, Caro J: Hypoxic regulation of the 6-phosphofructo-2-kinase/fructose-2,6-bisphosphatase gene family (PFKFB-I-4) expression in vivo. FEBS Lett 2003, 554:264-70.

42. Goidts V, Bageritz J, Puccio L, Nakata S, Zapatka M, Barbus S, Toedt G, Campos B, Korshunov A, Momma S, Van Schaftingen E, Reifenberger G, Herold-Mende C, Lichter P, Radlwimmer B: RNAi screening in glioma stem-like cells identifies PFKFB4 as a key molecule important for cancer cell survival. Oncogene 2012, 3I:3235-43.

43. Ros S, Santos CR, Moco S, Baenke F, Kelly G, Howell M, Zamboni N, Schulze A: Functional metabolic screen identifies 6-phosphofructo-2-kinase/fructose-2,6-biphosphatase 4 as an important regulator of prostate cancer cell survival. Cancer Discov 20I2, 2:328-43.

44. Bensaad K, Tsuruta A, Selak MA, Vidal MN, Nakano K, Bartrons R, Gottlieb E, Vousden KH: TIGAR, a p53-inducible regulator of glycolysis and apoptosis. Cell, 2006. I26(I): p. 107-20.

45. Berkers CR, Maddocks OD, Cheung EC, Mor I, Vousden $\mathrm{KH}$ : Metabolic regulation by p53 family members. Cell Metab 2013, 18:617-33.

46. Ren $\mathrm{F}, \mathrm{Wu} \mathrm{H}$, Lei $\mathrm{Y}$, Zhang $\mathrm{H}$, Liu R, Zhao Y, Chen X, Zeng D, Tong A, Chen L, Wei $Y$, Huang C: Quantitative proteomics identification of phosphoglycerate mutase $I$ as a novel therapeutic target in hepatocellular carcinoma. Mol Cancer 2010, 9:81.

47. Kondoh H, Lleonart ME, Gil J, Wang J, Degan P, Peters G, Martinez D, Carnero A, Beach D: Glycolytic enzymes can modulate cellular life span. Cancer Res 2005, 65:177-85.

48. Hitosugi T, Zhou L, Elf S, Fan J, Kang HB, Seo JH, Shan C, Dai Q, Zhang L, Xie J, Gu TL, Jin P, Alečković M, LeRoy G, Kang Y, Sudderth JA, DeBerardinis RJ, Luan CH, Chen GZ, Muller S, Shin DM, Owonikoko TK, Lonial S, Arellano ML, Khoury HJ, Khuri FR, Lee BH, Ye K, Boggon TJ, Kang S, He C, Chen J: Phosphoglycerate mutase I coordinates glycolysis and biosynthesis to promote tumor growth. Cancer Cell 20I2, 22:585-600.

\section{FlOOOPrime}

\section{RECOMMENDED}

49. Cairns RA, Harris IS, Mak TW: Regulation of cancer cell metabolism. Nat Rev Cancer 20I I, I I:85-95.

50. Christofk HR, Vander Heiden MG, Harris MH, Ramanathan A, Gerszten RE, Wei R, Fleming MD, Schreiber SL, Cantley LC: The M2 splice isoform of pyruvate kinase is important for cancer metabolism and tumour growth. Nature 2008, 452:230-3.

\section{FlOOOPrime RECOMMENDED}

5I. Riganti C, Gazzano E, Polimeni M, Aldieri E, Ghigo D: The pentose phosphate pathway: an antioxidant defense and a crossroad in tumor cell fate. Free Radic Biol Med 2012, 53:42I-36.

52. Deneke SM, Fanburg BL: Regulation of cellular glutathione. Am J Physiol 1989, 257:163-73.

53. Christofk HR, Vander Heiden MG, Wu N, Asara JM, Cantley LC: Pyruvate kinase M2 is a phosphotyrosine-binding protein. Nature 2008, 452: $181-6$.

\section{FlOOOPrime}

\section{RECOMMENDED}

54. Vander Heiden MG, Locasale JW, Swanson KD, Sharfi H, Heffron GJ, Amador-Noguez D, Christofk HR, Wagner G, Rabinowitz JD, Asara JM, Cantley LC: Evidence for an alternative glycolytic pathway in rapidly proliferating cells. Science 2010, 329:1492-9.

\section{FlOOOPrime}

55. Israelsen W], Dayton TL, Davidson SM, Fiske BP, Hosios AM, Bellinger G, Li J, Yu Y, Sasaki M, Horner JW, Burga LN, Xie J, Jurczak MJ, DePinho RA, Clish CB, Jacks T, Kibbey RG, Wulf GM, Di Vizio D, Mills GB, Cantley LC, Vander Heiden MG: PKM2 isoform-specific deletion reveals a 
differential requirement for pyruvate kinase in tumor cells. Cell 2013, I 55:397-409.

\section{FIOOOPrime}

56. Semenza GL: HIF-I: mediator of physiological and pathophysiological responses to hypoxia. J Appl Physiol (I985) 2000, 88: $1474-80$

57. Shim H, Dolde C, Lewis BC, Wu CS, Dang G, Jungmann RA, DallaFavera R, Dang CV: c-Myc transactivation of LDH-A: implications for tumor metabolism and growth. Proc Natl Acad Sci U S A 1997, 94:6658-63.

58. Fan J, Hitosugi T, Chung TW, Xie J, Ge Q, Gu TL, Polakiewicz RD, Chen GZ, Boggon TJ, Lonial S, Khuri FR, Kang S, Chen J: Tyrosine phosphorylation of lactate dehydrogenase $A$ is important for NADH/NAD(+) redox homeostasis in cancer cells. Mol Cell Biol 20II, 3 I:4938-50.

FlOOOPrime RECOMMENDED

59. Le A, Cooper CR, Gouw AM, Dinavahi R, Maitra A, Deck LM, Royer RE, Vander Jagt DL, Semenza GL, Dang CV: Inhibition of lactate dehydrogenase $A$ induces oxidative stress and inhibits tumor progression. Proc Natl Acad Sci U S A 2010, 107:2037-42.

\section{FlOOOPrime}

60. Fantin VR, St-Pierre J, Leder P: Attenuation of LDH-A expression uncovers a link between glycolysis, mitochondrial physiology, and tumor maintenance. Cancer Cell 2006, 9(6):425-34.

\section{FlOOOPrime} RECOMMENDED

6I. Ullah MS, Davies AJ, Halestrap AP: The plasma membrane lactate transporter MCT4, but not MCTI, is up-regulated by hypoxia through a HIF-I alpha-dependent mechanism. J Biol Chem 2006, 281:9030-7.

62. Le Floch R, Chiche J, Marchiq I, Naiken T, Ilc K, Murray CM, Critchlow SE, Roux D, Simon MP, Pouysségur J: CDI47 subunit of lactate/H+ symporters MCTI and hypoxia-inducible MCT4 is critical for energetics and growth of glycolytic tumors. Proc Natl Acad Sci U S A 201 I, 108:16663-8.

\section{FlOOPrime}

\section{RECOMMENDED}

63. Halestrap AP, Brand MD, Denton RM: Inhibition of mitochondrial pyruvate transport by phenylpyruvate and alphaketoisocaproate. Biochim Biophys Acta 1974, 367:102-8.

64. Bricker DK, Taylor EB, Schell JC, Orsak T, Boutron A, Chen YC, Cox JE, Cardon CM, Van Vranken JG, Dephoure N, Redin C, Boudina S, Gygi SP, Brivet M, Thummel CS, Rutter J: A mitochondrial pyruvate carrier required for pyruvate uptake in yeast, Drosophila, and humans. Science 2012, 337:96-100.

\section{FlOOOPrime} RECOMMENDED

65. Herzig S, Raemy E, Montessuit S, Veuthey JL, Zamboni N, Westermann B, Kunji ER, Martinou JC: Identification and functional expression of the mitochondrial pyruvate carrier. Science 2012, 337:93-6.

\section{FlOOOPrime}

66. Vacanti NM, Divakaruni AS, Green CR, Parker SJ, Henry RR, Ciaraldi TP, Murphy AN, Metallo CM: Regulation of Substrate Utilization by the Mitochondrial Pyruvate Carrier. Mol Cell 2014, 56:425-35

\section{FlOOOPrime} RECOMMENDED

67. Yang C, Ko BI, Hensley CT, Jiang L, Wasti AT, Kim J, Sudderth J, Calvaruso MA, Lumata L, Mitsche M, Rutter J, Merritt ME, DeBerardinis RJ: Glutamine Oxidation Maintains the TCA
Cycle and Cell Survival during Impaired Mitochondrial Pyruvate Transport. Mol Cell 20I4, 56:4l4-24.

\section{FIOOOPrime}

68. Schell JC, Olson KA, Jiang L, Hawkins AJ, Van Vranken JG, Xie J, Egnatchik RA, Earl EG, DeBerardinis RJ, Rutter J: A Role for the Mitochondrial Pyruvate Carrier as a Repressor of the Warburg Effect and Colon Cancer Cell Growth. Mol Cell 20I4, 56:400-4I3.

\section{FIOOOPrime
RECOMMENDED}

69. Holness MJ, Sugden MC: Regulation of pyruvate dehydrogenase complex activity by reversible phosphorylation. Biochem Soc Trans 2003, 31 : ||43-5|.

70. Sugden MC, Holness MJ: Recent advances in mechanisms regulating glucose oxidation at the level of the pyruvate dehydrogenase complex by PDKs. Am J Physiol Endocrinol Metab 2003, 284:E855-62.

7I. Papandreou I, Cairns RA, Fontana L, Lim AL, Denko NC: HIF-I mediates adaptation to hypoxia by actively downregulating mitochondrial oxygen consumption. Cell Metab 2006, 3:187-97.

\section{FlOOOPrime
RECOMMENDED}

72. Kim JW, Tchernyshyov I, Semenza GL, Dang CV: HIF-I-mediated expression of pyruvate dehydrogenase kinase: a metabolic switch required for cellular adaptation to hypoxia. Cell Metab 2006, 3: $177-85$.

\section{FlOOOPrime}

\section{RECOMMENDED}

73. Hitosugi T, Fan J, Chung TW, Lythgoe K, Wang X, Xie J, Ge Q, Gu TL, Polakiewicz RD, Roesel JL, Chen GZ, Boggon TJ, Lonial S, Fu H, Khuri FR, Kang S, Chen J: Tyrosine phosphorylation of mitochondrial pyruvate dehydrogenase kinase I is important for cancer metabolism. Mol Cell 20I I, 44:864-77.

\section{FIOOOPrime
RECOMMENDED}

74. Fan J, Shan C, Kang HB, Elf S, Xie J, Tucker M, Gu TL, Aguiar M, Lonning S, Chen H3, Mohammadi M, Britton LM, Garcia BA Alečković M, Kang Y, Kaluz S, Devi N, Van Meir EG, Hitosugi T, Seo JH, Lonial S, Gaddh M, Arellano M, Khoury HJ, Khuri FR, Boggon TJ, Kang S, Chen J: Tyr phosphorylation of PDPI toggles recruitment between ACATI and SIRT3 to regulate the pyruvate dehydrogenase complex. Mol Cell 2014, 53:534-48.

\section{FlOOOPrime \\ RECOMMENDED}

75. Bowker-Kinley MM, Davis WI, Wu P, Harris RA, Popov KM Evidence for existence of tissue-specific regulation of the mammalian pyruvate dehydrogenase complex. Biochem J 1998 , 329: $19 \mid-6$.

76. Bonnet S, Archer SL, Allalunis-Turner J, Haromy A, Beaulieu C, Thompson R, Lee CT, Lopaschuk GD, Puttagunta L, Bonnet S, Harry G, Hashimoto K, Porter CJ, Andrade MA, Thebaud B, Michelakis ED: A mitochondria-K+ channel axis is suppressed in cancer and its normalization promotes apoptosis and inhibits cancer growth. Cancer Cell 2007, I I:37-5 I

77. Knoechel TR, Tucker AD, Robinson CM, Phillips C, Taylor W, Bungay PJ, Kasten SA, Roche TE, Brown DG: Regulatory roles of the N-terminal domain based on crystal structures of human pyruvate dehydrogenase kinase $\mathbf{2}$ containing physiological and synthetic ligands. Biochemistry 2006, 45:402-I5.

78. Stacpoole PW: The pharmacology of dichloroacetate. Metabolism 1989, 38: | | 24-44.

79. Metallo CM, Vander Heiden MG: Understanding metabolic regulation and its influence on cell physiology. Mol Cell 2013, 49:388-98. 
80. DeBerardinis RJ, Cheng T: Q's next: the diverse functions of glutamine in metabolism, cell biology and cancer. Oncogene 2010, 29:313-24.

\section{FlOOOPrime}

\section{RECOMMENDED}

8I. Hensley CT, Wasti AT, DeBerardinis RJ: Glutamine and cancer: cell biology, physiology, and clinical opportunities. J Clin Invest 20I3, I23:3678-84.

82. Wise DR, DeBerardinis RJ, Mancuso A, Sayed N, Zhang $X Y$, Pfeiffer HK, Nissim I, Daikhin E, Yudkoff M, McMahon SB, Thompson CB: Myc regulates a transcriptional program that stimulates mitochondrial glutaminolysis and leads to glutamine addiction. Proc Natl Acad Sci U S A 2008, 105:18782-7.

\section{FlOOOPrime}

83. DeBerardinis RJ, Mancuso A, Daikhin E, Nissim I, Yudkoff M, Wehrli S, Thompson CB: Beyond aerobic glycolysis: transformed cells can engage in glutamine metabolism that exceeds the requirement for protein and nucleotide synthesis. Proc Natl Acad Sci U S A 2007, 104:19345-50.

84. Fan J, Ye J, Kamphorst JJ, Shlomi T, Thompson CB, Rabinowitz JD: Quantitative flux analysis reveals folate-dependent NADPH production. Nature 20I4, 5 I 0:298-302.

\section{FlOOOPrime \\ RECOMMENDE}

85. Mullen AR, Wheaton WW, jin ES, Chen PH, Sullivan LB, Cheng T, Yang Y, Linehan WM, Chandel NS, DeBerardinis RJ: Reductive carboxylation supports growth in tumour cells with defective mitochondria. Nature 2012, 48I:385-8.

\section{FlOOOPrime
RECOMMENDED}

86. Wise DR, Ward PS, Shay JE, Cross JR, Gruber JJ, Sachdeva UM, Platt JM, DeMatteo RG, Simon MC, Thompson CB: Hypoxia promotes isocitrate dehydrogenase-dependent carboxylation of alpha-ketoglutarate to citrate to support cell growth and viability. Proc Natl Acad Sci U S A 201 I, 108:1961 I-6.

\section{FlOOOPrime}

\section{RECOMMENDED}

87. Metallo CM, Gameiro PA, Bell EL, Mattaini KR, Yang J, Hiller K, Jewell CM, Johnson ZR, Irvine DJ, Guarente L, Kelleher JK, Vander Heiden MG, Iliopoulos O, Stephanopoulos G: Reductive glutamine metabolism by IDHI mediates lipogenesis under hypoxia. Nature 2012, 48I:380-4.

\section{FIOOOPrime}

88. Mullen AR, Hu Z, Shi X, Jiang L, Boroughs LK, Kovacs Z, Boriack R, Rakheja D, Sullivan LB, Linehan WM, Chandel NS, DeBerardinis RJ: Oxidation of alpha-ketoglutarate is required for reductive carboxylation in cancer cells with mitochondrial defects. Cell Rep 2014, 7:1679-90.

89. Gameiro PA, Laviolette LA, Kelleher JK, Iliopoulos O, Stephanopoulos G: Cofactor balance by nicotinamide nucleotide transhydrogenase (NNT) coordinates reductive carboxylation and glucose catabolism in the tricarboxylic acid (TCA) cycle. J Biol Chem 20I3, 288:12967-77.

90. Gameiro PA, Yang J, Metelo AM, Pérez-Carro R, Baker R, Wang Z, Arreola A, Rathmell WK, Olumi A, López-Larrubia P, Stephanopoulos G, lliopoulos O: In vivo HIF-mediated reductive carboxylation is regulated by citrate levels and sensitizes VHL-deficient cells to glutamine deprivation. Cell Metab 2013, 17:372-85.

91. Leonardi R, Subramanian C, Jackowski S, Rock CO: Cancerassociated isocitrate dehydrogenase mutations inactivate NADPH-dependent reductive carboxylation. J Biol Chem 2012, 287: $|46| 5-20$.

92. Mashima $T$, Seimiya $H$, Tsuruo $T$ : De novo fatty-acid synthesis and related pathways as molecular targets for cancer therapy. $\mathrm{Br} J$ Cancer 2009, 100:1369-72.
93. Yang YA, Han WF, Morin PJ, Chrest FJ, Pizer ES: Activation of fatty acid synthesis during neoplastic transformation: role of mitogen-activated protein kinase and phosphatidylinositol 3-kinase. Exp Cell Res 2002, 279:80-90.

94. Bauer DE, Hatzivassiliou G, Zhao F, Andreadis C, Thompson CB: ATP citrate lyase is an important component of cell growth and transformation. Oncogene 2005, 24:63।4-22.

95. Ward PS, Patel J, Wise DR, Abdel-Wahab O, Bennett BD, Coller HA, Cross JR, Fantin VR, Hedvat CV, Perl AE, Rabinowitz JD, Carroll M, Su SM, Sharp KA, Levine RL, Thompson CB: The common feature of leukemia-associated IDHI and IDH2 mutations is a neomorphic enzyme activity converting alpha-ketoglutarate to 2-hydroxyglutarate. Cancer Cell 2010, 17:225-34.

\section{FlOOOPrime
RECOMMENDED}

96. Dang L, White DW, Gross S, Bennett BD, Bittinger MA, Driggers EM, Fantin VR, Jang HG, Jin S, Keenan MC, Marks KM, Prins RM, Ward PS, Yen KE, Liau LM, Rabinowitz JD, Cantley LC, Thompson CB, Vander Heiden MG, Su SM: Cancer-associated IDHI mutations produce 2-hydroxyglutarate. Nature 2009, 462:739-44.

\section{FIOOOPRime
RECOMMENDED}

97. Ye D, Xiong $Y$, Guan KL: The mechanisms of IDH mutations in tumorigenesis. Cell Res 20I2, 22: I I02-4.

98. Xu W, Yang H, Liu Y, Yang Y, Wang P, Kim SH, Ito S, Yang C, Wang P, Xiao MT, Liu LX, Jiang WQ, Liu J, Zhang JY, Wang B, Frye S, Zhang Y, Xu YH, Lei QY, Guan KL, Zhao SM, Xiong Y: Oncometabolite 2-hydroxyglutarate is a competitive inhibitor of alphaketoglutarate-dependent dioxygenases. Cancer Cell 20II, 19:17-30.

\section{FlOOOPrime}

99. Figueroa ME, Abdel-Wahab O, Lu C, Ward PS, Patel J, Shih A, Li Y, Bhagwat N, Vasanthakumar A, Fernandez HF, Tallman MS, Sun Z, Wolniak K, Peeters JK, Liu W, Choe SE, Fantin VR, Paietta E, Löwenberg B, Licht JD, Godley LA, Delwel R, Valk PJ, Thompson CB, Levine RL, Melnick A: Leukemic IDHI and IDH2 mutations result in a hypermethylation phenotype, disrupt TET2 function, and impair hematopoietic differentiation. Cancer Cell 2010, 18:553-67.

FIOOOPRime
RECOMMENDED

100. Baysal $B E$ : On the association of succinate dehydrogenase mutations with hereditary paraganglioma. Trends Endocrinol Metab 2003, 14:453-9.

I0I. Baysal BE, Ferrell RE, Willett-Brozick JE, Lawrence EC, Myssiorek D, Bosch A, van der Mey A, Taschner PE, Rubinstein WS, Myers EN, Richard CW 3rd, Cornelisse C], Devilee P, Devlin B: Mutations in SDHD, a mitochondrial complex II gene, in hereditary paraganglioma. Science 2000, 287:848-5I.

102. Tomlinson IP, Alam NA, Rowan AJ, Barclay E, Jaeger EE, Kelsell D, Leigh I, Gorman P, Lamlum H, Rahman S, Roylance RR, Olpin S, Bevan S, Barker K, Hearle N, Houlston RS, Kiuru M, Lehtonen R, Karhu A, Vilkki S, Laiho P, Eklund C, Vierimaa O, Aittomäki K, Hietala M, Sistonen P, Paetau A, Salovaara R, Herva R, Launonen V, Aaltonen LA; Multiple Leiomyoma Consortium: Germline mutations in FH predispose to dominantly inherited uterine fibroids, skin leiomyomata and papillary renal cell cancer. Nat Genet 2002, 30:406-10.

103. Kaelin WG Jr., Ratcliffe PJ: Oxygen sensing by metazoans: the central role of the HIF hydroxylase pathway. Mol Cell 2008, 30:393-402.

104. Semenza GL: HIF-I, O(2), and the 3 PHDs: how animal cells signal hypoxia to the nucleus. Cell 200I, 107:I-3.

105. Schofield C], Zhang Z: Structural and mechanistic studies on 2oxoglutarate-dependent oxygenases and related enzymes. Curr Opin Struct Biol 1999, 9:722-3I.

106. Smith EH, Janknecht R, Maher LJ 3rd: Succinate inhibition of alpha-ketoglutarate-dependent enzymes in a yeast model of paraganglioma. Hum Mol Genet 2007, 16:3136-48. 
107. Selak MA, Armour SM, MacKenzie ED, Boulahbel H, Watson DG, Mansfield KD, Pan Y, Simon MC, Thompson CB, Gottlieb E: Succinate links TCA cycle dysfunction to oncogenesis by inhibiting HIF-alpha prolyl hydroxylase. Cancer Cell 2005, 7:77-85

\section{FlOOOPrime} RECOMMENDED

108. Pollard PJ, Brière JJ, Alam NA, Barwell J, Barclay E, Wortham NC, Hunt T, Mitchell M, Olpin S, Moat SJ, Hargreaves IP, Heales SJ, Chung YL, Griffiths JR, Dalgleish A, McGrath JA, Gleeson MJ, Hodgson SV, Poulsom R, Rustin P, Tomlinson IP: Accumulation of Krebs cycle intermediates and over-expression of HIF Ialpha in tumours which result from germline $\mathrm{FH}$ and SDH mutations. Hum Mol Genet 2005, 14:223I-9.

109. Morin A, Letouzé E, Gimenez-Roqueplo AP, Favier J: Oncometabolites-driven tumorigenesis: From genetics to targeted therapy. Int J Cancer 20I4, 135:2237-48.

I 10. Vega-Naredo I, Loureiro R, Mesquita KA, Barbosa IA, Tavares LC, Branco AF, Erickson JR, Holy J, Perkins EL, Carvalho RA, Oliveira PJ: Mitochondrial metabolism directs stemness and differentiation in PI9 embryonal carcinoma stem cells. Cell Death Differ 20I4, 2I:I560-74.

FlOOOPrime

RECOMMENDED 